\title{
Diagnosis and Management of Chronic Kidney Disease- Mineral Bone Disease in Children
}

\author{
Jin-Soon Suh, M.D., Ph.D. \\ Department of Pediatrics, Bucheon St. \\ Mary's Hospital, College of Medicine, \\ The Catholic University of Korea, Seoul, \\ Republic of Korea \\ Corresponding author: \\ Jin-Soon Suh, M.D, Ph.D. \\ Department of Pediatrics, Bucheon St. \\ Mary's Hospital, College of Medicine, The \\ Catholic University of Korea, 327, Sosa- \\ ro, Bucheon-si, Gyeonggi-do, 14647, \\ Republic of Korea \\ Tel: +82-32-340-7047 \\ Fax: +82-32-340-2673 \\ E-mail: rebekahjs@hanmail.net
}

Received: 11 March 2020

Revised: 27 March 2020

Accepted: 24 April 2020
This is an open-access article distributed under the terms of the Creative Commons Attribution Non-Commercial License (http:// creativecommons.org/licenses/by-nc/4.0/) which permits unrestricted non-commercial use, distribution, and reproduction in any medium, provided the original work is properly cited.

Copyright (C) 2020 The Korean Society of Pediatric Nephrology
Chronic kidney disease-mineral bone disorder (CKD-MBD) is a systemic disorder of mineral and bone metabolism caused by CKD. Patients with early-stage CKD who present with disordered regulation of bone and mineral metabolism may be asymptomatic. However, if untreated, the condition can be a significant barrier in achieving optimal bone strength, linear growth, and cardiovascular health in pediatric patients with CKD. Thus, the current study evaluated the definition, pathogenesis, diagnosis, and management of pediatric CKD-MBD.

Key words: Chronic kidney disease, Mineral Bone Disorder, Children, Growth

\section{Introduction}

Chronic kidney disease (CKD) is defined as the presence of either structural or functional kidney damage, with or without a decrease in glomerular filtration rate (GFR) or a GFR $<60 \mathrm{~mL} / \mathrm{min} / 1.73 \mathrm{~m}^{2}$, and with or without signs of kidney damage for $>3$ months ${ }^{1)}$. To stratify the risk of CKD progression and its complications, the condition was classified into five stages on the basis of GFR levels (Table 1). Children with stage 1-2 CKD are commonly asymptomatic and should be followed-up for the deterioration of renal function. By contrast, children with more advanced stages of CKD experience CKD-associated complications, including fluid and electrolyte disorders, hypertension, anemia, growth impairment, and mineral bone disorder $(\mathrm{MBD})^{2)}$. The current study focused on the diagnosis and management of CKD-MBD.

\section{Definition of CKD-MBD}

Dysregulation in mineral metabolism and abnormal bone structure are common findings among pediatric CKD patients, and they contribute to high morbidity and mortality ${ }^{3}$. CKD-MBD is defined as the presence of one or more of the following problems: (1) abnormalities in calcium, phosphorus, and parathyroid hormone (PTH) levels or vitamin D metabolism; (2) problems in bone turnover, mineralization, linear growth, or strength; and 3) vascular or other soft tissue calcifications ${ }^{4}$. Children with CKD who present with CKD-BMD may develop significant complications, including fractures and bone pain, similar to those observed in adult CKD patients; complica- 
tions, such as growth failure and skeletal deformities are unique among children. The term renal osteodystrophy specifically refers to abnormal bone lesions, which are identified through bone biopsy.

\section{Pathogenesis of CKD-MBD}

The pathogenesis of CKD-MBD involves an interplay among the kidney, bone, and parathyroid glands. In the early stages of CKD, fibroblastic growth factor 23 (FGF23) levels increase, and serum phosphate and PTH levels remain within normal ranges ${ }^{5}$. With the progression of CKD, phosphate retention caused by decreased renal phosphorus excretion increases the levels of phosphaturic hormones, FGF23, and PTH, which is a mechanism that maintains serum phosphorus concentration ${ }^{6,7)}$. In addition, phosphate retention results in a decrease in 1,25-dihydroxyvitamin D levels to reduce enteral phosphate absorption ${ }^{7}$. Elevated FGF23 levels further decrease 1,25-dihydroxyvitamin D levels by inhibiting 1-hydroxylase activity in the kidney, and this leads to a reduction in 1,25-dihydroxyvitamin D levels caused by decreased 1-hydroxylation of 25-hydroxyvitamin D levels ${ }^{8}$. Phosphate retention and 1,25-dihydroxyvitamin D deficiency decrease calcium levels, and low 1,25-dihydroxyvitamin D levels and hypocalcemia contribute to secondary hyperparathyroidism ${ }^{8)}$. Increased PTH activity in the bone results in high bone turnover and resorption, which weakens the bones and increases both calcium and phosphate levels--this mechanism may promote vascular calcification ${ }^{9)}$.

Table 1. Stages for Chronic Kidney Disease by Glomerular Filtration Rate (GFR) Categories

\begin{tabular}{cccl}
\hline Stage & $\begin{array}{c}\text { GFR } \\
\text { category }\end{array}$ & $\begin{array}{c}\text { GFR } \\
\left(\mathrm{mL} / \mathrm{min} / 1.73 \mathrm{~m}^{2}\right)\end{array}$ & \multicolumn{1}{c}{ Description } \\
\hline 1 & G1 & $\geq 90$ & $\begin{array}{l}\text { Kidney damage with normal or } \\
\text { increased GFR }\end{array}$ \\
2 & G2 & $60-89$ & $\begin{array}{l}\text { Kidney damage with mild decrease } \\
\text { in GFR }\end{array}$ \\
3 & G3a & $45-59$ & $\begin{array}{l}\text { Mild to moderate decrease in GFR } \\
4\end{array}$ \\
\hline 5 & G3b & $30-44$ & $\begin{array}{l}\text { Moderate to severe decrease in GFR } \\
\text { G5 }\end{array}$ \\
\hline
\end{tabular}

\section{Screening and monitoring of CKD-MBD}

The Kidney Disease: Improving Global Outcomes (KDIGO) and the Kidney Disease Outcomes Quality Initiative (K/DOQI) guidelines recommend that the serum calcium, phosphate, and PTH levels and the alkaline phosphatase activity should be monitored in children with stage $2 \mathrm{CKD}^{2,10)}$. The reasonable monitoring intervals are summarized in Table 2. Moreover, the frequency of measurements for children treated for CKD-MBD should be increased to monitor treatment efficacy and side effects. The PTH level is negatively correlated with renal function, although the optimal PTH levels of pediatric CKD patients have not been identified ${ }^{11)}$. The K/DOQI guideline shows that the recommended target PTH concentrations at each stage of CKD are as follows: $35-70 \mathrm{pg} / \mathrm{mL}$ in stages $2-3$, $70-110 \mathrm{pg} / \mathrm{mL}$ in stage 4 , and $200-300 \mathrm{pg} / \mathrm{mL}$ in stage $5^{2}$. The KDIGO guideline recommends maintaining PTH levels within approximately 2-9 times the upper normal limit for patients on dialysis. If the PTH level is progressively increasing or persistently above the upper limit of the normal value, patients who are not on dialysis should be evaluated for modifiable risk factors, including hyperphosphatemia, hypocalcemia, and vitamin $\mathrm{D}$ deficiency ${ }^{10}$. A modest increase in PTH levels indicates an appropriate adaptive response to declining kidney function in patients with stage 2-5 CKD, with consideration of the potential adverse effects of reducing PTH values with the use of active vitamin D or calcimimetics. Thus, recently, several experts have shown that maintaining PTH levels within the normal range may be harmful in children with $\mathrm{CKD}^{12-14)}$. Moreover, PTH values that are 1-2 times the upper normal limit may be acceptable in children with stage 2-3 CKD, and PTH levels

Table 2. Recommended Monitoring Intervals of Serum Calcium, Phosphate and Parathyroid Hormone Levels in CKD Patients

\begin{tabular}{|c|c|c|c|c|}
\hline \multirow{2}{*}{ CKD Stage } & \multicolumn{2}{|c|}{ K/DOQI guideline $e^{2)}$} & \multicolumn{2}{|c|}{ KDIGO guideline ${ }^{10)}$} \\
\hline & Serum $\mathrm{Ca} / \mathrm{P}$ & PTH & Serum Ca/P & PTH \\
\hline 2 & yearly & yearly & NA & NA \\
\hline 3 & 6 months & 6 months & 6-12 months & 6 months* \\
\hline 4 & 3 months & 3 months & $3-6$ months & $6-12$ months \\
\hline 5 & monthly & 3 months & $1-3$ months & $3-6$ months \\
\hline
\end{tabular}

*The intervals can be adjusted based on the baseline PTH level and the rate of CKD progression.

Abbreviations: CKD, chronic kidney disease; K/DOQI, the Kidney Disease Outcomes Quality Initiative; KDIGO, The Kidney Disease: Improving Global Outcomes; Ca, calcium; P, phosphate; PTH, parathyroid hormone. 
that are 1.7-5 times the upper normal limit may be optimal in those with stage $4-5 \mathrm{CKD}^{12}$. Thus, further studies must be conducted to define the optimal PTH level according to the CKD stage in children ${ }^{12,15)}$.

\section{Treatment of CKD-MBD}

The therapeutic goal of pediatric CKD-MBD is to prevent or minimize complications in the growing skeleton, achieve adequate growth, and prevent vascular calcification by managing hyperphosphatemia, vitamin D deficiency, and secondary hyperparathyroidism ${ }^{3,16}$. The options for achieving the therapeutic goal include dietary modification, use of pharmacological agents, and surgical treatment. To date, to provide better treatment options for pediatric patients with CKD-MBD, several randomized controlled trials (RCTs) have compared the efficacy and safety between different treatment modalities, such as calcium-based phosphate binders versus calcium-free phosphate binders, vitamin $D$ versus placebo, and calcimimetics versus placebo 13,17,18).

When there is a progressive or persistent increase in phosphate levels, treatments for lowering these levels toward the normal range are required ${ }^{10)}$. The serum phosphate concentration is highest in infants, and its normal value decreases as the child ages. The target serum phosphate levels are approximately $5.0-8.0 \mathrm{mg} / \mathrm{dL}$ for infants, 4-6 $\mathrm{mg} / \mathrm{dL}$ for children aged $1-12$ years, and $3.5-5.5 \mathrm{mg} / \mathrm{dL}$ in adolescents ${ }^{19)}$. Phosphate binders in combination with dietary phosphorus restriction are frequently used to lower serum phosphate levels. The K/DOQI guideline indicates that dietary phosphate intake should be limited to $100 \%$ of the dietary reference intake (DRI) for age when the serum PTH concentration is above the target range for CKD stage, and the serum phosphate concentration is within the normal reference range for age, and is limited to $80 \%$ of the DRI for age when both serum PTH and serum phosphate levels are above the target range ${ }^{19)}$. However, maintaining compliance with dietary phosphate restriction is challenging in children because most of their favorite foods are rich in phosphate. Therefore, phosphate binders are often required to correct hyperphosphatemia, and calcium-based and calcium-free phosphate binders are also available. Ge- nerally, calcium-based phosphate binders, such as calcium carbonate and calcium acetate, are used as an initial therapy because they are cheap, well-tolerated, and effective in lowering serum phosphate and PTH levels ${ }^{20}$. However, there is a concern about calcium overload and vascular calcification with the use of these drugs. In patients with hypercalcemia, calcium-free phosphate binders are preferred $^{21,22)}$. Some calcium-free phosphate binders that are commonly used in pediatric CKD patients are sevelamer hydrochloride and sevelamer carbonate. Lanthanum carbonate is another type of calcium-free phosphate binder, which is effective. Recent RCTs showed that compared with calcium-based binders, calcium-free binders can significantly reduce the risk of hypercalcemia, coronary artery calcification, and mortality in CKD patients ${ }^{17,22,23)}$. Ironbased phosphate binders, including ferric citrate, were recently developed to correct the common CKD comorbidities of hyperphosphatemia and iron deficiency anemia ${ }^{24)}$. In 2014, ferric citrate was approved by the U.S. Food and Drug Administration for adult CKD patients on dialysis. It was well-tolerated and associated with decreased phosphate levels and improved iron parameters in a study on a small group of pediatric dialysis patients, similar to that seen in adult CKD patients. However, larger clinical trials must be conducted to validate the safety and efficacy of these drugs in the pediatric population ${ }^{25}$. Aluminum- and magnesium-based phosphate binders are also non-calciumbased binders. However, the long-term use of these drugs is not recommended for pediatric CKD patients. Aluminum accumulation in the tissues, particularly bone and brain tissues, can cause bone disease and neurologic complications, including encephalopathy and neurocognitive dysfunction ${ }^{3,26)}$. In addition, magnesium-containing binders may predispose patients to hypermagnesemia and frequent diarrhea ${ }^{3)}$. Phosphate binders should be taken 10-15 minutes before or during meals. If taken between meals, the phosphate-lowering effect is decreased because most dietary phosphates have already been absorbed. Moreover, phosphate binders have a limited phosphate-binding capacity. Therefore, these drugs may be effective in lowering serum phosphate levels only if dietary phosphate restriction is maintained ${ }^{16)}$.

Vitamin D deficiency is common and often severe in children and adults with $\mathrm{CKD}^{27}$. Treatment of vitamin $\mathrm{D}$ 
deficiency is important because vitamin D deficiency contributes to secondary hyperparathyroidism. Therefore, serum 25-hydroxyvitamin D levels should be monitored regularly in stage 2 CKD patients and maintained at $>30$ $\mathrm{ng} / \mathrm{mL}$, but not exceeding $48 \mathrm{ng} / \mathrm{mL}$, in children with stage $2-5 \mathrm{CKD}^{28)}$. In patients with serum 25 -hydroxyvitamin $\mathrm{D}$ levels $<30 \mathrm{ng} / \mathrm{mL}$, vitamin D2 (ergocalciferol) or vitamin D3 (cholecalciferol) treatment is recommended ${ }^{19,28)}$. In a randomized, double-blind, placebo-controlled study in children with stage 2-4 CKD, ergocalciferol was found to be effective as it delays the development of secondary hyperparathyroidism $^{18)}$. Several guidelines present the starting dose and duration of vitamin $\mathrm{D}$ supplementation in pediatric CKD patients based on the severity of vitamin $\mathrm{D}$ deficiency and the age or weight of the patients ${ }^{19,28)}$. Active vitamin $\mathrm{D}$ analogue, including calcitriol, is recommended for children with CKD who present with serum PTH concentrations consistently above the target range even if the serum 25 -hydroxyvitamin D levels are not low $(\geq 30 \mathrm{ng} / \mathrm{mL})^{29}$. During treatment, serum calcium, phosphate, and 25-hydroxyvitamin D levels should be monitored monthly for electrolytes and at 3 month-intervals for serum 25-hydroxyvitamin D levels.

Calcimimetics, including cinacalcet, that increase the sensitivity of the calcium-sensing receptor in the parathyroid gland to calcium, can be used for severe hyperparathyroidism in CKD patients ${ }^{30)}$. Studies of pediatric CKD patients, including a recent $\mathrm{RCT}$, showed that the use of cinacalcet is effective in reducing parathyroid hormone levels in children with hyperparathyroidism. However, the long-term effects have not yet been assessed ${ }^{13,31)}$. For patients with refractory hyperparathyroidism that does not respond to medical or pharmacological therapy, parathyroidectomy may be indicated $^{10)}$.

\section{Conclusion}

Abnormalities in mineral and bone metabolism are common and important complications of CKD. Patients with these complications may be asymptomatic. Moreover, these complications can occur in the early stages of CKD. Therefore, screening and monitoring of serum electrolyte, PTH, and vitamin D concentrations as well as that of ade- quate linear growth are recommended for all children with CKD beginning at stage 2 of the disease. Prevention and treatment include dietary management and/or use of medications to maintain the optimal levels of electrolytes and related hormones, and these strategies should be individualized in this group of patients.

\section{Conflicts of interest}

No potential conflict of interest relevant to this article was reported.

\section{References}

1. Andrassy KM. Comments on 'KDIGO 2012 Clinical Practice Guideline for the Evaluation and Management of Chronic Kidney Disease'. Kidney Int 2013;84:622-3.

2. Hogg RJ, Furth S, Lemley KV, Portman R, Schwartz GJ, Coresh J, et al. National Kidney Foundation's Kidney Disease Outcomes Quality Initiative clinical practice guidelines for chronic kidney disease in children and adolescents: evaluation, classification, and stratification. Pediatrics 2003;111(6 Pt 1):1416-21.

3. Hanudel MR, Salusky IB. Treatment of Pediatric Chronic Kidney Disease-Mineral and Bone Disorder. Curr Osteoporos Rep 2017; 15:198-206.

4. Wesseling K, Bakkaloglu S, Salusky I. Chronic kidney disease mineral and bone disorder in children. Pediatr Nephrol 2008;23: 195-207.

5. Isakova T, Wahl P, Vargas GS, Gutierrez OM, Scialla J, Xie H, et al. Fibroblast growth factor 23 is elevated before parathyroid hormone and phosphate in chronic kidney disease. Kidney Int 2011; 79:1370-8.

6. Saito H, Maeda A, Ohtomo S, Hirata M, Kusano K, Kato S, et al. Circulating FGF-23 is regulated by 1alpha,25-dihydroxyvitamin D3 and phosphorus in vivo. J Biol Chem 2005;280:2543-9.

7. Portale AA, Booth BE, Halloran BP, Morris RC, Jr. Effect of dietary phosphorus on circulating concentrations of 1,25-dihydroxyvitamin $\mathrm{D}$ and immunoreactive parathyroid hormone in children with moderate renal insufficiency. J Clin Invest 1984;73:1580-9.

8. Naveh-Many T, Silver J. The Pas de Trois of Vitamin D, FGF23, and PTH. J Am Soc Nephrol 2017;28:393-5.

9. Goodman WG, Goldin J, Kuizon BD, Yoon C, Gales B, Sider D, et al. Coronary-artery calcification in young adults with end-stage renal disease who are undergoing dialysis. N Engl J Med 2000; 342:1478-83.

10. Kidney Disease: Improving Global Outcomes CKDMBDUWG. KDIGO 2017 Clinical Practice Guideline Update for the Diagnosis, 
Evaluation, Prevention, and Treatment of Chronic Kidney DiseaseMineral and Bone Disorder (CKD-MBD). Kidney Int Suppl (2011) 2017;7:1-59.

11. Ziolkowska H, Paniczyk-Tomaszewska M, Debinski A, Polowiec Z, Sawicki A, Sieniawska M. Bone biopsy results and serum bone turnover parameters in uremic children. Acta Paediatr 2000;89: 666-71.

12. Haffner D, Leifheit-Nestler M. Treatment of hyperphosphatemia: the dangers of aiming for normal PTH levels. Pediatr Nephrol 2020;35:485-91.

13. Warady BA, lles JN, Ariceta G, Dehmel B, Hidalgo G, Jiang X, et al. A randomized, double-blind, placebo-controlled study to assess the efficacy and safety of cinacalcet in pediatric patients with chronic kidney disease and secondary hyperparathyroidism receiving dialysis. Pediatr Nephrol 2019;34:475-86.

14. Haffner D, Leifheit-Nestler M. Extrarenal effects of FGF23. Pediatr Nephrol 2017;32:753-65.

15. Bacchetta J. Treatment of hyperphosphatemia: the dangers of high PTH levels. Pediatr Nephrol 2020;35:493-500.

16. McAlister L, Pugh P, Greenbaum L, Haffner D, Rees L, Anderson $C$, et al. The dietary management of calcium and phosphate in children with CKD stages 2-5 and on dialysis-clinical practice recommendation from the Pediatric Renal Nutrition Taskforce. Pediatr Nephrol 2020;35:501-18.

17. Fathallah-Shaykh S, Drozdz D, Flynn J, Jenkins R, Wesseling-Perry K, Swartz SJ, et al. Efficacy and safety of sevelamer carbonate in hyperphosphatemic pediatric patients with chronic kidney disease. Pediatr Nephrol 2018;33:325-33.

18. Shroff R, Wan M, Gullett A, Ledermann S, Shute R, Knott C, et al. Ergocalciferol supplementation in children with CKD delays the onset of secondary hyperparathyroidism: a randomized trial. Clin J Am Soc Nephrol 2012;7:216-23.

19. Group KW. KDOQI Clinical Practice Guideline for Nutrition in Children with CKD: 2008 update. Executive summary. Am J Kidney Dis 2009;53(3 Suppl 2):S11-104.

20. Andreoli SP, Dunson JW, Bergstein JM. Calcium carbonate is an effective phosphorus binder in children with chronic renal failure. Am J Kidney Dis 1987;9:206-10.

21. Mahdavi H, Kuizon BD, Gales B, Wang HJ, Elashoff RM, Salusky IB. Sevelamer hydrochloride: an effective phosphate binder in dia- lyzed children. Pediatr Nephrol 2003;18:1260-4.

22. Habbous S, Przech S, Acedillo R, Sarma S, Garg AX, Martin J. The efficacy and safety of sevelamer and lanthanum versus calciumcontaining and iron-based binders in treating hyperphosphatemia in patients with chronic kidney disease: a systematic review and meta-analysis. Nephrol Dial Transplant 2017;32:111-25.

23. Sekercioglu N, Thabane L, Diaz Martinez JP, Nesrallah G, Longo CJ, Busse JW, et al. Comparative Effectiveness of Phosphate Binders in Patients with Chronic Kidney Disease: A Systematic Review and Network Meta-Analysis. PLoS One 2016;11:e0156891.

24. Floege J, Covic AC, Ketteler M, Rastogi A, Chong EM, Gaillard S, et al. A phase III study of the efficacy and safety of a novel ironbased phosphate binder in dialysis patients. Kidney Int 2014;86: 638-47.

25. Hanudel MR, Laster M, Ramos G, Gales B, Salusky IB. Clinical experience with the use of ferric citrate as a phosphate binder in pediatric dialysis patients. Pediatr Nephrol 2018;33:2137-42.

26. Andreoli SP, Bergstein JM, Sherrard DJ. Aluminum intoxication from aluminum-containing phosphate binders in children with azotemia not undergoing dialysis. N Engl J Med 1984;310:107984.

27. Portale AA, Wolf M, Juppner $H$, Messinger S, Kumar J, WesselingPerry K, et al. Disordered FGF23 and mineral metabolism in children with CKD. Clin J Am Soc Nephrol 2014;9:344-53.

28. Shroff R, Wan M, Nagler EV, Bakkaloglu S, Fischer DC, Bishop N, et al. Clinical practice recommendations for native vitamin D therapy in children with chronic kidney disease Stages 2-5 and on dialysis. Nephrol Dial Transplant 2017;32:1098-113.

29. Shroff R, Wan M, Nagler EV, Bakkaloglu S, Cozzolino M, Bacchetta $J$, et al. Clinical practice recommendations for treatment with active vitamin D analogues in children with chronic kidney disease Stages 2-5 and on dialysis. Nephrol Dial Transplant 2017;32:111427.

30. Investigators ET, Chertow GM, Block GA, Correa-Rotter R, Drueke $T B$, Floege J, et al. Effect of cinacalcet on cardiovascular disease in patients undergoing dialysis. N Engl J Med 2012;367:2482-94.

31. Joseph C, Shah S, Geer J, Juarez-Calderon M, Srivaths PR, Swartz SJ. Cinacalcet for secondary hyperparathyroidism in end-stage renal disease patients below age 5 years. Clin Nephrol 2019;92: 279-86. 